Article

\title{
Environmental Education to Change the Consumption Model and Curb Climate Change
}

\author{
Leticia-Concepción Velasco-Martínez ${ }^{1}$, Juan-Jesús Martín-Jaime ${ }^{2}$, Ligia-Isabel Estrada-Vidal ${ }^{3}$ \\ and Juan-Carlos Tójar-Hurtado ${ }^{2, * 10}$ \\ 1 Department of Research and Psychology in Education, Complutense University of Madrid, \\ 28040 Madrid, Spain; letivela@ucm.es \\ 2 Department of Research Methods in Education, University of Malaga, 29071 Malaga, Spain; jjmartin@uma.es \\ 3 Department of Research Methods in Education, University of Granada, 52005 Granada, Spain; ligia@ugr.es \\ * Correspondence: jctojar@uma.es; Tel.: +34-952-132-543
}

Received: 29 July 2020; Accepted: 8 September 2020; Published: 11 September 2020

check for updates

\begin{abstract}
Environmental education plays a fundamental role in the fight against climate change and the transformation towards a more sustainable and environmentally friendly socio-economic model. This study shows how to evaluate the effectiveness of a program for compulsory education students in Spain. The subject of the program focused on the effects of climate change in relation to our consumption model and the generation of waste. A mixed research methodology is proposed that combines a quantitative (10 items on the Likert scale, $n=714)$ and qualitative approach (category construction and analysis on open-ended questions). A study of the reliability and validity of the measure was carried out through a categorical principal component analysis (CATPCA). The multivariate analysis of variance (MANOVA) correlates the gender and educational level of the students to the learning acquired in the program. For example, the results show how students are convinced that adopting minimal pro-environmental habits (turning off lights and unplugging electronics, choosing public transport to get around, or using solar and wind power to produce electricity) can help mitigate climate change. The conclusions show the difficulties and challenges of education for responsible consumption, emphasizing the development of environmental education programs for reducing the effects of climate change.
\end{abstract}

Keywords: environmental education; consumption; climate change; program evaluation; sustainable development; compulsory education

\section{Introduction}

Climate change has become a global socio-environmental problem taken on by the scientific community, by most governments and administrations, and by a large part of the public. However, some authors [1] insist that society must accept that we are no longer working to prevent climate change, but to mitigate its effects and facilitate adaptation to the proposed changes. In this respect, the Intergovernmental Panel on Climate Change (IPCC) has just presented an assessment report (AR6) on limiting the global temperature increase to $1.5^{\circ} \mathrm{C}$ in relation to pre-industrial levels. This report points out that in the coming decades, we must achieve rapid and far-reaching transitions in energy, land use, urban management (transport and construction), and industrial systems, combining unprecedented efforts involving a reduction in the energy demand, a change in material consumption, and a reduction in food consumption in terms of greenhouse gases [2]. These emissions are causing increasingly frequent and devastating climate events and natural disasters: more severe cyclones and hurricanes, heat waves, fires, torrential rains and extreme droughts, rising sea levels from melting glaciers, earthquakes, volcanic eruptions, and landslides [3]. 
Consumer organizations [4] also warn of the problems caused by this system of production and consumption, which are becoming increasingly serious: increasing world poverty, child labor, unequal conditions for large groups of the population, pollution and the deterioration of natural resources, the increase in the Earth's temperature, natural disasters, new health problems, etc. All of the above demonstrate that this model of consumption is not sustainable, resulting in a high environmental and social cost for our planet.

As we know, consuming does not only mean buying. From the start of the day, our lifestyle and daily habits are associated with the consumption of different resources (water, electricity, transport, waste production, etc.), which result in $\mathrm{CO}_{2}$ emissions produced by the dependence on fossil fuels (coal, oil, natural gas, etc.) [5]. For instance, $91 \%$ of emissions in Spain are the result of fossil fuel consumption in power plants, vehicles, industries, shops, and homes [6]. Committing to integrated resource management allows for more efficient savings of raw materials and contributes to reducing the increase in greenhouse gas emissions and, consequently, the consequences of climate change. Along with political and scientific-technical strategies and actions, we must incorporate agents of change from other social sectors. In this line, organizations and institutions related to communication, information, and, particularly, education, are responsible for contributing to knowledge and understanding on this issue [7]. It has sometimes been observed that climate change plans are "closed door documents" without citizen participation, and even that local officials do not consider stakeholder participation necessary to develop climate change plans [8]. However, other authors stress that it is essential that the educational community incorporates activities aimed at supporting the processes of reflection, awareness, and action in its projects and work programs in the face of climate change [9].

In this sense, environmental education plays a fundamental role in the fight against environmental degradation and the transformation towards a more sustainable and environmentally friendly socio-economic model. Following the Paris Agreement and the Sustainable Development Goals (SDGs), the United Nations Development Program is reviewing the unsustainable consumption and production models of large industrialized countries, which represent one of the main causes of the degradation of our planet (deforestation, water scarcity, food waste, loss of biodiversity, etc.). In this regard, according to SDG 12 (Ensure sustainable consumption and production patterns), one of the goals to be highlighted in the scope of the new Agenda 2030 is to make a transition to more responsible and sustainable modes of consumption. This transition is aimed at the management and efficient use of natural resources; the reduction of waste generation through policies of prevention, reduction, recycling, and reuse; and the transmission of information and knowledge to develop habits, behaviors, and lifestyles in harmony with nature [10]. In addition, the achievement of SDG 12 has, among its goals, the creation of synergies and support for the achievement of other objectives related to water, food, and energy, contributing to the mitigation of climate change. In coordination with SDG 12, Agenda 2030 also proposes, through SDG 13 (Climate action), a roadmap for the development of climate actions to reduce emissions and combat the threat of climate change and its effects. Within the goals of SDG 13, it is envisaged that a better response in the field of education, awareness raising, and the training of citizens and institutions with regard to mitigation, adaptation, and reduction of the impacts of climate change will be provided.

From this perspective, the SDGs are aligned with the aims of environmental education in terms of its purpose of forming a citizenry aware of the causes and consequences of climate change and other environmental problems, and equipping it with the knowledge, skills, and attitudes needed to respond to the current development model. Hermans and Korhonen [11] point out the need, interest, and relevance of including environmental education in strategies to combat climate change. The aims of environmental education should be established in relation to climate change, by making a diagnosis of the current social situation, as well as a review of the obstacles and difficulties in implementing programs and activities. Moreover, according to Hadjichambis, Paraskeva-Hadjichambi, and Ioannou [12], it is stated that teaching activities and didactic programs should take into account education on values, including aspects of education for consumption and respect for the environment. 
In this regard, Novo [13] states that environmental education is a key element in the process of the ecological transition towards more sustainable societies that are capable of quickly grasping contexts and emergency situations, organizing resources, and anticipating solutions and implementing them. To this end, it is essential to design educational programs that provide students with knowledge about the different socio-environmental problems that are linked to the current development model and its impact on global warming, and the systems of mass production and consumption: the supply and demand market, toxic elements, the $\mathrm{CO}_{2}$ concentration, waste generation, job insecurity, health, natural disasters, migration, poverty, etc.

With this framework in mind, this article aims to highlight the implementation of environmental education programs aimed at providing knowledge and encouraging a critical attitude on the influence of our consumption habits on waste generation, climate change, and the loss of natural resources. Therefore, the objective of this study is to contrast an evaluation proposal of the Education Program "Change my Consumption Model". The purpose of this program is to know and identify the phases of the life cycle of urban solid waste that is deposited in the waste management center of the city of Malaga (Spain), for its treatment, recovery, and elimination. Malaga is the sixth largest city in Spain in terms of population and is the largest coastal city in southern Europe. Its 574,654 inhabitants (2019) generate 1 million tons of waste per year. The "Change my Consumption Model" program also aims to promote debate and critical analysis of our consumption patterns, related to our behavior, daily habits, and lifestyle, and their consequences for the environment. The program includes different visits to waste treatment plants located in the waste management center in Malaga, as well as the projection of a video in an environmental classroom. In addition, activities are carried out to raise awareness of the importance of correct waste management through the 3 Rs rule (reduce, reuse, and recycle), and participation and collaboration in waste separation are encouraged. Subsequently, an educational itinerary is made along a path located around the treatment plants to raise awareness of the natural, scenic, and cultural value of the environment where the waste management center is located. During the route, stops are made in strategic areas of a natural path and a series of viewpoints to reflect on the origin, effects, and prevention of some of the environmental problems on an urban scale, related to the loss of biodiversity, climate change, and the appropriate management of solid urban waste. This program is aimed at the educational community of Malaga, especially at primary and secondary school students. This environmental education program is in turn part of a "Green Passport" macro-program of the Malaga City Council.

Despite the important advances in recent years in the development of educational strategies and environmental education programs [8], there still seem to be controversies and shortcomings in the implementation of mechanisms and processes for evaluating the impact and scope of these training and educational awareness programs [14]. Therefore, this study proposes an evaluation to find out the direct effects of the Environmental Education Program "Change my Consumption Model" on the improvement of learning, understanding, and acquisition of pro-environmental behaviors, as well as on the adoption of values and attitudes necessary to develop a sustainable lifestyle and a critical attitude towards the challenges of climate change. Environmental knowledge and attitudes change as students mature and as they go through school. It is, therefore, essential to take into account the level of education and relate it to learning on and attitudes towards a new model of consumption that will curb climate change.

The gender of the students is another variable to take into account. Several studies have pointed out the importance of always considering gender when conducting research on environmental education [15]. In some cases [16], gender and age differences are observed in the teaching of SDGs. However, on other occasions, gender differences have not been so evident when environmental awareness among secondary school students is taken into account [17].

In order to analyze the changes and transformation related to the implementation of the program, the following research questions are posed: 
- Do the activities proposed in the environmental education program improve participants' learning about the environmental impact of our consumption model and waste generation on climate change mitigation?

- Do the participants analyze the reality of the current model of consumption, evaluating more sustainable, fair, and supportive alternatives, in relation to the consumerist way of life?

- Do participants identify that consumption habits, such as shopping, types of food, transport, or energy saving, influence the emission of greenhouse gases and are part of climate change mitigation and adaptation strategies?

- Do the activities developed in the environmental education program promote a critical and reflective attitude towards environmental problems (waste generation, depletion of natural resources, loss of biodiversity, etc.) caused by the adoption of unsustainable consumption habits?

- Are participants in the environmental education program aware of good practices for responsible consumption to reduce environmental pollution and the effects of climate change?

- Can the educational level and gender of the participants, separately or interacting, influence what is learned from the environmental education program?

\section{Objectives}

The general objective of this research is to evaluate an environmental education program. The evaluation was carried out to determine the capacity of the mentioned program to improve environmental knowledge and attitudes as previous steps to promote a change of consumption model that helps to curb climate change. When this program was evaluated, the educational level (primary and secondary compulsory education) and gender were taken into account for their possible modulating effects on learning and changes in attitudes.

The specific objectives of this work are as follows:

1. To understand the previous knowledge that students of compulsory education have about climate change in different contexts and learning situations (school, extracurricular activities, and own home);

2. To identify the level of information and training on the severity of climate change that students possess;

3. To assess the degree of reflection of students on the impact of domestic consumption habits on climate change;

4. To obtain the level of perception that students have in relation to the existence of solutions to the problems of climate change;

5. To analyze the extent to which students associate the impact of everyday actions with the effects of climate change (switching off lights, unplugging appliances, using reusable bags, taking public transport, using renewable energy, etc.);

6. To determine the influence that the educational level and gender may have on knowledge and behavior change for curbing climate change; and

7. To obtain the scope and variety of what students in compulsory education learn from their own opinions.

\section{Materials and Methods}

A mixed method approach was conducted in terms of the CUAN $\rightarrow$ cual design, including explanatory sequential mixed methods, according to the classification of Creswell [18]. The quantitative approach was applied through a survey study involving the design, validation, and application of a questionnaire (Appendix A). The qualitative approach was developed through a procedure of qualitative analysis of the open-ended items of the questionnaire, following the proposal of Miles, Huberman, and Saldaña [19]. 
The instrument was constructed from an extensive review of the scientific literature that allowed the design of a first version of the questionnaire to respond to the objectives and research problem posed. Afterwards, the characteristics of the sample were determined, in order to adapt the questionnaire to the particularities of the population analyzed. Once the instrument had been developed, it was validated by six experts in the field (environmental education and research methodology) and, subsequently, the reliability and validity of the measure obtained through the application of the questionnaire were analyzed. The analysis included a reliability study (internal consistency), based on Cronbach's alpha coefficient; a factorial analysis; and a categorical principal component analysis (CATPCA), taking into account the ordinal and nominal nature of the data [20].

\subsection{Sample}

Expert sampling [21] was carried out, considering essential criteria for the research: (a) being a student in the last three years of primary or compulsory secondary education and (b) actively participating in the "Change my Consumption Model" program. All participants who met these criteria were incorporated into the sample. Therefore, a sample of 714 students was selected (52.8\% girls and $47.2 \%$ boys). The average age of the students was 12.9 years $(\mathrm{SE}=0.11)$. Students belonging to primary education represent $57.1 \%$ of the sample, and those coming from compulsory secondary education courses represent $41.1 \%$. The participants in the program came from 15 schools in the city of Malaga.

\subsection{Analysis Procedure}

The questionnaire prepared (Appendix A) was organized on a Likert scale ranging from 0 (strongly disagree) to 5 (strongly agree), and was structured on the basis of the following dimensions:

- Dimension 1: Level of prior knowledge about climate change in different learning contexts and situations (school, out-of-school activities, and home)

- Dimension 2: Level of information on the severity of climate change

- Dimension 3: Level of perception about the impact of domestic consumption habits on climate change

- Dimension 4: Level of response to climate change issues

- Dimension 5: Level of contribution of everyday actions to climate change mitigation and adaptation (turning off lights, unplugging appliances, using reusable bags, taking public transport, using renewable energy, etc.)

The questionnaire was organized into three parts (Appendix A):

1. Identification data (center, educational level, age, and gender)

2. Ten close-ended questions, including five questions belonging to dimensions 1,2 , and 3 to be answered before applying the program, and five questions referring to dimensions 4 and 5 to be answered after applying the program

3. Two open-ended questions: the first one to express positive and negative aspects of the program's activities, and the second one to indicate knowledge or experiences acquired during the program

The categorical principal component analysis (CATPCA) confirmed the structure of the 10 close-ended questions. Figure 1 shows how the first five questions were organized in component 1 (dimensions 1, 2, and 3, before the program) and the second five questions were organized in component 2 (dimensions 4 and 5, after the program). The total Cronbach's alpha obtained through CATPCA was 0.88 . 


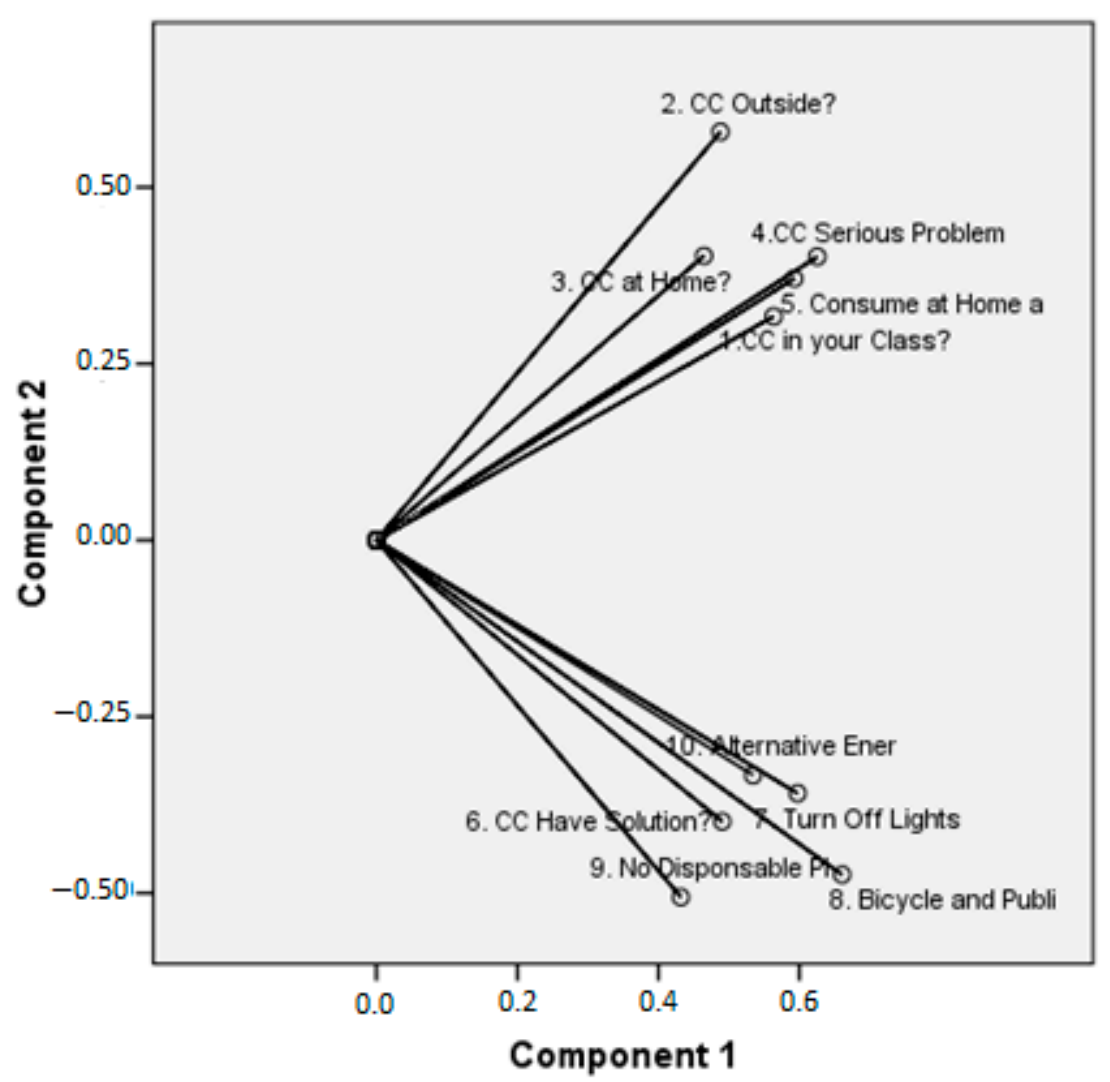

Figure 1. Categorical principal component analysis (CATPCA)—graphic representation of items and components.

Descriptive analyses were carried out (frequencies, percentages, means, and standard errors), and $t$-tests were calculated by relating all the items of the questionnaire, separately, to gender and educational level, which consisted of primary and secondary education (independent variables). In the same way, all dependent variables (questionnaire items) and independent variables (gender and educational level) were included in a single design, for which a multivariate analysis of variance (MANOVA) was used. In the results section, only multivariate analyses will be reported, since they are equivalent to bivariate analyses (comparing means), while at the same time, they are more sensitive in detecting significant differences and they also allow for the analysis of the interaction between independent variables. All quantitative data processing was performed using the SPSS v24 statistical analysis package.

A primary qualitative analysis was carried out on the open-ended questions through processes of reduction, categorization, and the construction of typologies. This was supported by the qualitative analysis program Atlas.ti v7.

\section{Results}

In this section, the results achieved are briefly presented. First, the descriptive results are shown and, later, the results of the analysis of the comparison of measures from the MANOVA are presented. Finally, a summary of the qualitative results obtained is presented.

\subsection{Descriptive Results}

Table 1 presents the items of the questionnaire, using a Likert scale from 0 (totally disagree) to 5 (totally agree), with the mean and standard deviation values obtained. 
Table 1. Means and standard deviations of questionnaire items.

\begin{tabular}{ccc} 
Items & Mean & Standard Deviation \\
\hline Did you learn about climate change in your classes? & 3.19 & 1.05 \\
class (excursions)? & 2.81 & 1.12 \\
Had you learned about climate change in other activities outside of & 2.78 & 1.17 \\
Have you learned about climate change at home? & 3.72 & 1.30 \\
Did you think that climate change was a serious problem? & 3.30 & 0.98 \\
Did you think that what you consume at home can affect changes in \\
the climate? & 3.98 & 0.88 \\
$\begin{array}{c}\text { Do you think that the problems of climate change have a solution? } \\
\text { Do you think it is important to turn off lights and unplug electronics } \\
\text { when you are not using them? }\end{array}$ & 4.47 & 0.85 \\
$\begin{array}{c}\text { Do you think it is important to use your bicycle, or public transport, } \\
\text { to reduce climate change? }\end{array}$ & 4.37 & 1.10 \\
Do you plan not to use disposable plastic bags or reduce the \\
consumption of over-packaged products?
\end{tabular}

Source: Own elaboration.

As shown in Table 1, prior to the implementation of the education program, students indicated that they have learned more about climate change in their classes (item 1) compared to other academic activities outside the classroom (item 2), and even more than what they have learned at home (item 3). Additionally, it is notable that the item referring to the severity of climate change is one of the most valued (3.72 out of 5). Regarding the questions asked after the application of the program, it should be noted that the students are very much in agreement with developing certain habits and behaviors that can mitigate the effects of climate change. These include turning off lights and unplugging electronic devices when not in use (4.47), using a bicycle or public transport (4.37), and using solar and wind energy to produce electricity (4.36). Reducing the use of disposable plastic bags or over-packaged products is slightly less valued (3.88). However, it is necessary to highlight that students seem to believe that the problems of climate change have a solution (3.98).

\subsection{Multivariate Analysis}

In order to carry out the multivariate contrasts (MANOVA), Pillai's trace, Wilks' lambda, Hotelling's trace, and Roy's Largest Root were calculated. The $F$ tests carried out contrasted the multivariate effect by educational level and gender. Table 2 shows the contrasts used to accept or reject the null hypotheses of independence between the items of the questionnaire and the educational level and gender. In addition, the calculation of the size of the effect from the partial coefficient $\eta^{2}$ has been included.

Table 2 shows the relevance of the educational level in the model (significant $p$-values with an effect size of 0.19). Gender does not seem to have much of an influence. However, if we look at the interception of the model, the effect size rises to 0.891 . In the inter-subject effect tests conducted, the relevance in the model of the educational level is again shown (seven out of ten contrasts are significant), and the low relevance of gender (only one significant contrast, with a low effect size). Table 3 includes the evidence of significant inter-subject effects, including, in each case, the effect size. Although all significant contrasts are shown $(p \leq 0.005)$, the effect sizes are small. 
Table 2. Multivariate analysis of variance (MANOVA) contrasts tests.

\begin{tabular}{ccccccc}
\hline Effect & Contrast & Value & $\boldsymbol{F}$ & Hp $d f$ & $p$ & Effect Size \\
\hline Interception & Pillai's trace & 0.981 & 3024.51 & 10 & 0.00 & 0.98 \\
& Wilks' lambda & 0.019 & 3024.51 & 10 & 0.00 & 0.98 \\
& Hotelling's trace & 50.662 & 3024.51 & 10 & 0.00 & 0.98 \\
& Roy's Largest Root & 50.662 & 3024.51 & 10 & 0.00 & 0.98 \\
Gender & Pillai's trace & 1.26 & 1.27 & 10 & 0.24 & 0.02 \\
& Wilks' lambda & 0.98 & 1.27 & 10 & 0.24 & 0.02 \\
& Hotelling's trace & 0.88 & 1.27 & 10 & 0.24 & 0.02 \\
Educational level & Roy's Largest Root & 0.85 & 1.27 & 10 & 0.24 & 0.02 \\
& Pillai's trace & 1.26 & 13.65 & 10 & 0.00 & 0.19 \\
& Wilks' lambda & 0.98 & 13.65 & 10 & 0.00 & 0.19 \\
Gender X & Hotelling's trace & 0.88 & 13.65 & 10 & 0.00 & 0.19 \\
Educational level & Roy's Largest Root & 0.85 & 13.65 & 10 & 0.00 & 0.19 \\
& Pillai's trace & 1.26 & 0.55 & 10 & 0.85 & 0.01 \\
& Wilks' lambda & 0.98 & 0.55 & 10 & 0.85 & 0.01 \\
& Hotelling's trace & 0.88 & 0.55 & 10 & 0.85 & 0.01 \\
& Roy's Largest Root & 0.85 & 0.55 & 10 & 0.85 & 0.01 \\
\hline
\end{tabular}

Source: Own elaboration.

Table 3. MANOVA contrast tests.

\begin{tabular}{|c|c|c|c|c|}
\hline Effect & Items & $F$ & $p$ & Effect Size \\
\hline Gender & $\begin{array}{c}\text { Did you think that what you consume at home can affect } \\
\text { changes in the climate? }\end{array}$ & 4.94 & 0.027 & 0.08 \\
\hline \multirow[t]{7}{*}{ Educational level } & Did you learn about climate change in your classes? & 7.91 & 0.005 & 0.01 \\
\hline & $\begin{array}{l}\text { Had you learned about climate change in other activities } \\
\text { outside of class (excursions)? }\end{array}$ & 19.69 & 0.000 & 0.03 \\
\hline & Have you learned about climate change at home? & 11.46 & 0.001 & 0.02 \\
\hline & Did you think that climate change was a serious problem? & 92.14 & 0.000 & 0.13 \\
\hline & $\begin{array}{c}\text { Did you think that what you consume at home can affect } \\
\text { changes in the climate? }\end{array}$ & 5.65 & 0.018 & 0.01 \\
\hline & $\begin{array}{l}\text { Do you plan not to use disposable plastic bags or reduce the } \\
\text { consumption of over-packaged products? }\end{array}$ & 21.48 & 0.000 & 0.03 \\
\hline & $\begin{array}{l}\text { Do you think it is important to use solar and wind energy to } \\
\text { produce electricity? }\end{array}$ & 4.17 & 0.041 & 0.01 \\
\hline
\end{tabular}

Source: Own elaboration.

With regard to gender, only one significant difference can be observed. Although both genders have a medium-high average, girls are more aware that what is consumed at home can affect climate change (3.42) than boys (3.15). This difference is significant, with $F=4.94$ and $p=0.027\left(\eta^{2}=0.08\right)$.

With regard to the level of education, after the analysis of variance, several significant differences could also be observed. For example, students in secondary education have learned more about climate change in their classes (mean $=3.28$ ) than those in primary education (mean $=3.04)$. This difference is significant with $F=7.91$ and $p=0.005$. Furthermore, it seems that students in secondary education have learned more about climate change outside of class (mean $=2.96)$ than those in primary education (mean $=2.54$ ). This difference is significant with $F=19.69$ and $p \leq 0.0005$. In addition, the students in secondary education also seem to have learned more about climate change at home (mean $=2.88)$ than those in primary education (mean $=2.61$ ). This difference is significant with $F=11.458$ and $p=0.001$. In relation to the perception of the seriousness of climate change, students in secondary education believe that climate change is a more serious problem $(\mathrm{mean}=4.06)$ than students in primary education (mean $=3.15$ ). This difference is significant with $F=92135$ and $p \leq 0.0005$. The results also indicate that students in secondary education are more aware that what is consumed at home can affect climate change (mean $=3.36)$ than students in primary education (mean $=3.18)$. This difference is significant with $F=5.652$ and $p=0.018$. 
In the last two items, there are also differences between the primary and secondary groups. In the case of not using disposable plastic bags or reducing the consumption of over-packaged products, primary students (mean $=4.13$ ) were more aware than secondary students (mean $=3.73$ ). In this case, the analysis of variance gave $F=21.48$ and $p \leq 0.0005$. In the case of the importance of using solar and wind energy to produce electricity, primary students seem to be more aware (mean $=4.46$ ) than secondary students (mean $=4.29$ ). In this case, the analysis of variance also offered significant results with $F=4.17$ and $p=0.041$.

\subsection{Open-Ended Questions Analysis}

To complement the information on the Likert scale items, two more open-ended questions were added. One of them was included so that the participants in the program could indicate the most positive or negative aspects of the program, and the second one was included so that they could point out a word or concept that they had learned.

For the analysis of the content of these questions, a qualitative analysis was carried out, taking the literal expressions of the students collected in the questionnaire (Appendix A) as units. Literal expressions, such as text fragments, were present at both the time of selection and throughout the processes of categorization, analysis, and elaboration of conclusions [22].

Processes of reduction, data availability, and elaboration and verification of conclusions were applied to the information collected. To this end, techniques such as classification and categorization, models, and typologies were used. Through a process of increasing abstraction, the data produced took on the form of theory. Based on the processes of analysis mentioned above, matrices and explanatory graphs were developed [19,23]. To facilitate the qualitative analyses, the program Atlas.ti v7.0 (2012) was used.

After the analysis of the transcripts of the question on "Positive and negative aspects of the activity", 161 literal quotations were selected. Two macro-categories were constructed from these quotations: One referring to the lessons learned and the other to the evaluation of the program. These macro-categories were organized into 10 categories and 44 subcategories, as shown in Table 4 .

With regard to the most positive or negative aspects of the program, there is a predominance of favorable ratings and comments over adverse opinions. As a positive aspect, the acquisition of valuable lessons, such as those referring to the knowledge on fauna and flora of the natural environment, or topics related to consumption, recycling, climate change, or the values associated with care for and respect of the environment, are highlighted. Moreover, the level of satisfaction of the students in relation to the development and result of the program is shown. As negative aspects, some difficulties expressed by the students regarding the realization of the didactic itinerary through the path are pointed out.

In relation to the question on concepts learned, common names of plants and animals are highlighted including oil, gilthead, palm, asparagus, horehound, cochineal, carob, oak, wild olive, fox, rockrose, but also the original stones of the area, such as "sandstone". It is interesting to stop at some more complex striking concepts, such as "anthropic", "anthropomorphic", "climate change", "biodiversity", "clean point", "monopolize", "consumption", or "civility", referring to the need to become aware of our influence on ecosystems and the challenges we face in contributing to the sustainable development of the planet. 
Table 4. Macro-categories extracted from the analysis of the question on "positive and negative aspects of the activity".

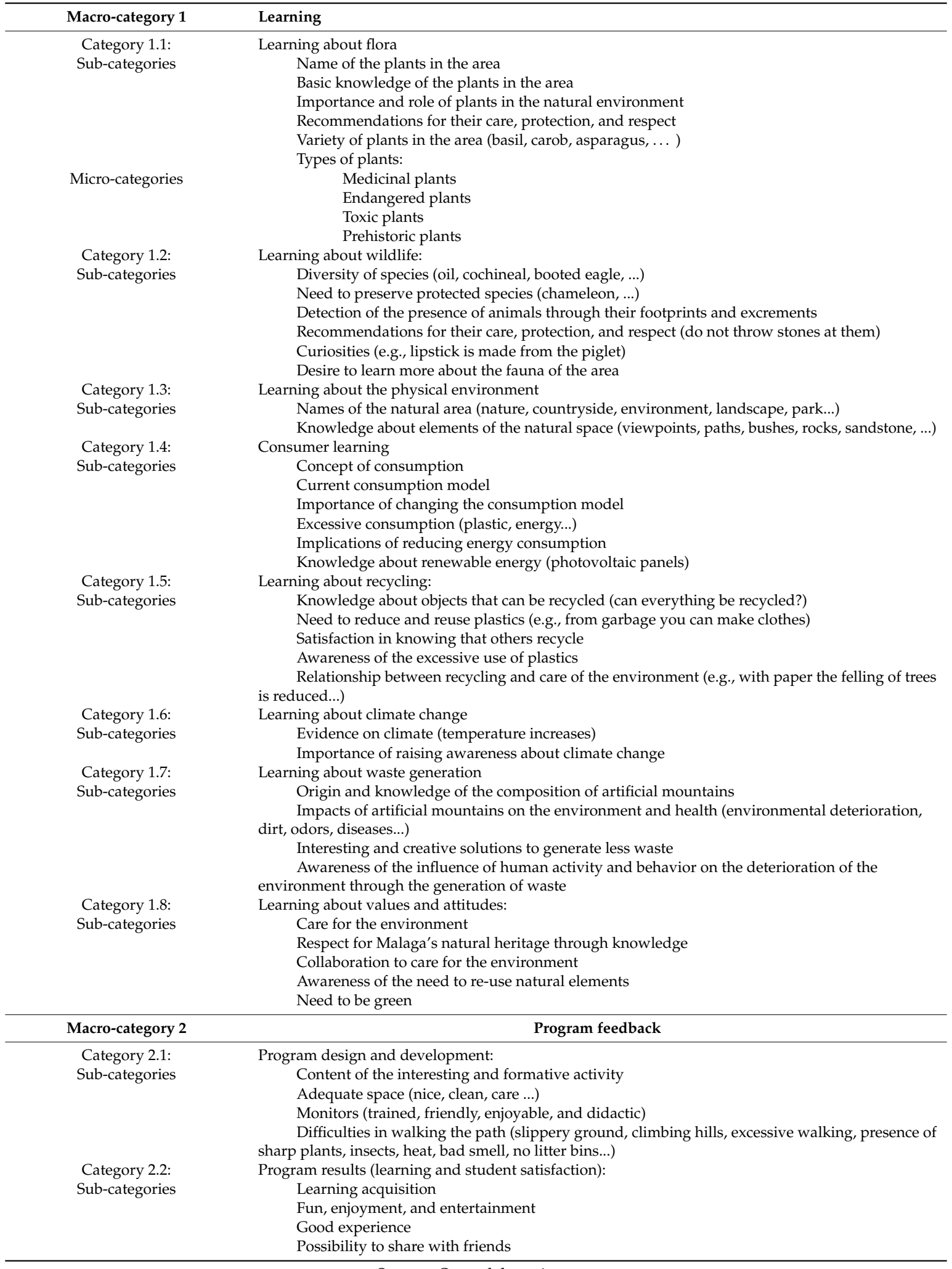

Source: Own elaboration. 


\section{Discussion and Conclusions}

Environmental education programs encourage the acquisition of values, attitudes, and behaviors, both at an individual and collective level, for contributing to the adoption of more sustainable lifestyles and consumption habits that are more consistent with the environmental challenges of our society [24]. In this regard, it is important to evaluate the climate change plans developed to advance our understanding of the local climate change planning process and identify current socio-environmental issues [25]. More specifically, the evaluation of this program shows the importance of this type of educational proposal for facilitating young people's knowledge and understanding of our development model in relation to the impact it has on the global warming of our planet. In this sense, García-Díaz [26] also points out that these programs should be aimed at raising awareness and sensitizing not only of the characteristics of the problem and its consequences (e.g., the nature of the greenhouse effect and its relevance to climate change), but also of the various social interests at stake and the political reasons for what is happening (e.g., the US policy of rejecting international agreements that limit its energy waste), it being clear that it is necessary to take advantage of the few loopholes left by the system for criticism and social transformation (sense of resistance and solidarity with people and groups that share this position) [26] (p. 5).

From this perspective, the debate focuses on the importance of promoting educational plans that allow young people, as active consumers, to become aware of the importance of their decisions and to develop their sense of responsibility [12].

In the same line, $\mathrm{Li}$ [25] indicates that it is also interesting to note that many jurisdictions contemplate encouraging "low carbon lifestyles" to respond to climate change. Eighty-eight percent of the provinces and $94 \%$ of the case cities in China recommend educating citizens about low carbon concepts in their plans. In addition, $63 \%$ of the cities have low carbon transit encouragement programs, and $38 \%$ of the local jurisdictions have low carbon product promotion strategies in their plans [25] (p. 89).

Empowering and sensitizing citizens to this knowledge and power can lay the foundation for the transformation to a new economic model by and for people and the planet [27]. In this line, environmental education plays a key role in the development of initiatives and projects focused on encouraging young people to develop responsible consumption habits that involve an awareness of the choice of more environmentally sustainable products. However, it also requires motivating them to make efforts to adopt consumption habits that seek to reduce consumption by eliminating superfluous needs and take into account production mechanisms and systems that demand less materials and energy [4]. All these actions are decisive for working on the dimensions of the impact of climate change on a local and global scale.

Based on this premise, the results of this study suggest that environmental education programs can contribute to training in strategies and guidelines for action to mitigate the effects of climate change through activities aimed at promoting appropriate behavioral patterns, energy-saving measures, and changes in diet and the reduction of waste from the food sector.

With regard to the measures taken by young people to reduce the effects of climate change, the results found in the study conducted by Tesa-Alosno [28] coincide with ours in pointing out that young people allude to the consumption and production of energy as one of the main causes of environmental deterioration and climate change, together with the use of cars and household appliances. Additionally, this study raises an important criticism about the link between climate change and the current consumption model that reinforces the results of our study. This author states that the experts indicate that when these issues are addressed, the root of the prevailing economic, social, and environmental model is not questioned. They also point out that the solutions and responses do not involve the option of a debate on the consumer society, and do not reflect the need for cultural transformation. Moreover, they point out that there are issues such as the overexploitation of natural resources that are not seen as problems related to climate change; on the contrary, they are perceived as being in favor of the economy [25]. In her study, the author also insists that "environmental education projects and actions are presented as solutions through simple individual gestures (energy efficiency, 
mobility, waste treatment), which are considered insufficient" (p. 256). In this sense, the program that has been evaluated goes beyond exclusively raising awareness about the adoption of measures to respond to climate change, and also promotes reflections on the problems of the consumption model and the economic system prevailing in our society.

According to UNICEF [5], from the results obtained, primary education is considered to be an ideal educational stage for showing students that the climate acts as a complex system whose variations respond to different causes which do not come from a single responsible person, and that their effects are not totally predictable and can affect us in many ways. In addition, students begin to be prepared to know about and understand the relationships between climate change and our lifestyle from a dual perspective: how our consumption patterns affect global warming and how climate change may force us to modify our habits. Furthermore, the secondary education [5] results point out that it is essential to address knowledge and understanding of climate change by explaining the life cycle of consumer products and the concepts of respect and care for the environment (including reuse, recycling, and conservation of environmental resources), and by analyzing the environmental and social impact of consumer goods before they are purchased. The differences found between education levels show how younger students (primary education) are somewhat more optimistic about solutions to climate change. Students in compulsory secondary education naturally have a greater knowledge of some issues and are beginning to show a more critical attitude. The results obtained in terms of age are consistent with the research of Sakellari and Skanavis [15], but not in relation to gender. As shown in the results of this research, as was also the case for Olsson and Gericke [16], there are hardly any differences between boys and girls. According to the didactic proposal of UNICEF [5], we consider that this program has proved to be effective in relation to the achievement of its objectives, being consistent with international educational action lines on climate change.

Similarly, the results of this study show that the participation of schoolchildren in environmental education programs encourages attitudes and behaviors that are more consistent with decreasing the depletion of natural resources, the generation of waste, and the effects of climate change. Participants in the activities indicate that they are convinced that adopting minimum pro-environmental habits (such as turning off lights and unplugging electronic devices, choosing public transport for travel, or using solar and wind energy to produce electricity) can help mitigate climate change. Moreover, schoolchildren warn of concerns about the massive use of plastic bags and consumption of over-packaged products, although they attach relative importance to this. However, it should be noted that the greatest contribution made by this educational program is raising awareness among schoolchildren of the relationship between the consumption model and global warming, supporting the perception that the problems of climate change have a solution. Therefore, it can be concluded that the program is effective insofar as it has made schoolchildren aware of the seriousness of the problem of climate change, favoring the acquisition of values, attitudes, and behaviors in the education sector that are responsible for our environment in relation to sustainable consumption.

In addition, the results of this article show the challenges of education for responsible consumption and the implementation of actions to mitigate climate change. In the same way, the results highlight the development of environmental education programs that address the problems of our current development model, with a critical and responsible attitude. Furthermore, based on this work, all sectors of our society are encouraged to join efforts to help young people identify the issues they consider relevant, to propose solutions that they believe will work, and to devise action plans within their reach.

Author Contributions: Conceptualization, L.-C.V.-M. and J.-C.T.-H.; methodology, L.-I.E.-V. and J.-C.T.-H.; validation, L.-C.V.-M., J.-J.M.-J., and J.-C.T.-H.; formal analysis, L.-I.E.-V. and J.-C.T.-H.; investigation, L.-C.V.-M. and J.-J.M.-J.; resources, L.-C.V.-M. and J.-J.M.-J.; data curation, L.-I.E.-V. and J.-C.T.-H.; writing-original draft preparation, L.-C.V.-M. and J.-C.T.-H.; writing-review and editing, L.-C.V.-M., J.-J.M.-J., and L.-C.V.-M.; supervision, J.-C.T.-H. All authors have read and agreed to the published version of the manuscript.

Funding: This research received no external funding. 
Acknowledgments: Malaga City Council, and Aula del Mar S.C.A./Alborania Museum, responsible for the Environmental Education Program "Change My Consumption Model".

Conflicts of Interest: The authors declare no conflict of interest.

\section{Appendix A}

Questionnaire on the Program: Change My Consumption Model*

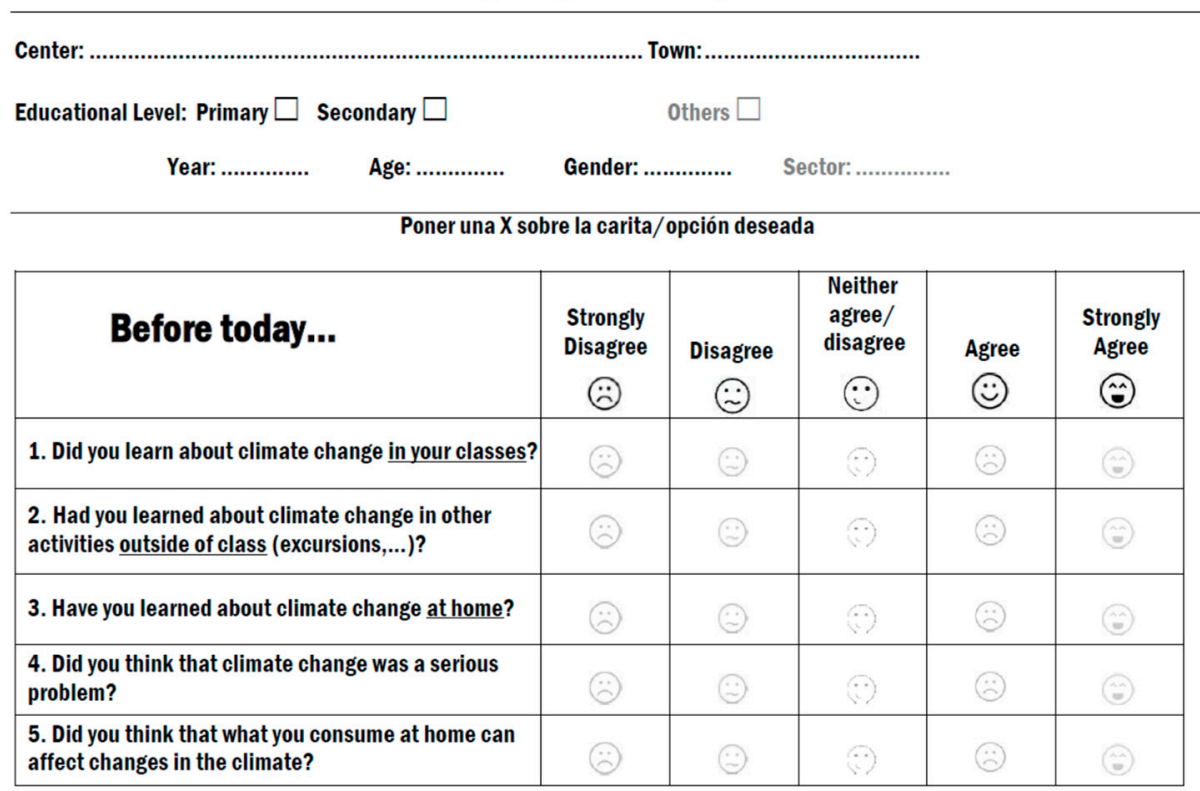

\begin{tabular}{|l|c|c|c|c|c|}
\hline \multicolumn{1}{|c|}{ After today... } & $\begin{array}{c}\text { Strongly } \\
\text { Disagree }\end{array}$ & Disagree & $\begin{array}{c}\text { Neither } \\
\text { agree/ } \\
\text { disagree }\end{array}$ & Sgree & $\begin{array}{c}\text { Strongly } \\
\text { Agree }\end{array}$ \\
\hline $\begin{array}{l}\text { 6. Do you think that the problems of climate change } \\
\text { have a solution? }\end{array}$ & & & & & \\
\hline $\begin{array}{l}\text { 7. Do you think it is important to turn off lights } \\
\text { and unplug electronics when you are not using } \\
\text { them? }\end{array}$ & & & & & \\
\hline $\begin{array}{l}\text { 8. Do you think it is important to use your bicycle, or } \\
\text { public transport, to reduce climate change? }\end{array}$ & & & & & \\
\hline $\begin{array}{l}\text { 9. Do you plan not to use disposable plastic bags } \\
\text { or reduce the consumption of over-packaged } \\
\text { products? }\end{array}$ & & & & & \\
\hline $\begin{array}{l}\text { 10. Do you think it is important to } \\
\text { use solar and wind energy to produce } \\
\text { electricity? }\end{array}$ & & & & & \\
\hline
\end{tabular}

Comment on something, positive or negative, that has drawn your attention to what you have experienced today:

Point out some word or concept you didn't know and learned today:

* Malaga City Hall. Environment and Sustainability Area. Section of Biodiversity and Environmental Education.

Juan-Carlos Tójar-Hurtado // Leticia-C. Velasco-Martínez // Juan-Jesús Martín-Jaime. University of Malaga 2019

Figure A1. Questionnaire on the Program "Change My Consumption Model”. 


\section{References}

1. Krasny, M.E.; DuBois, B. Climate adaptation education: Embracing reality or abandoning environmental values. Environ. Educ. Res. 2019, 25, 883-894. [CrossRef]

2. IPCC (Intergovernmental Panel on Climate Change). IPCC Special Report on 1.5 C Headline Statements; IPCC: Geneva, Switzerland, 2015. Available online: http://report.ipcc.ch/sr15/pdf/sr15_headline_statements.pdf/ (accessed on 17 May 2020).

3. Sánchez-Mojica, B.E. La Migración en el Contexto de Cambio Climático y Desastres: Reflexiones para la Cooperación Española; Instituto de Estudios sobre Conflictos y Acción Humanitaria (IECAH): Madrid, Spain, 2019.

4. FACUA. Yo También Consumo de Forma Responsable; Facua Andalucía: Sevilla, Spain, 2018.

5. UNICEF. Educación, Derechos de Infancia y Cambio Climático; UNICEF Comité Español: Madrid, Spain, 2018.

6. Secretaría Confederal de Medio Ambiente y Movilidad de Comisiones Obreras. Evolución de las Emisiones de Gases de Efecto Invernadero en España (1990-2017); Confederación Sindical de Comisiones Obreras: Madrid, Spain, 2018.

7. Rousell, D.; Cutter-Mackenzie-Knowles, A. A systematic review of climate change education: Giving children and young people a 'voice' and a 'hand' in redressing climate change. Children's Geogr. 2020, 18, 191-208. [CrossRef]

8. Li, C.; Song, Y. Government Response to Climate Change in China: A Study of Provincial and Municipal Plans. J. Environ. Plan. Manag. 2016, 59, 1679-1710. [CrossRef]

9. Monroe, M.C.; Plate, R.E.; Oxarart, A.; Bowers, A.; Chaves, W.A. Identifying effective climate change education strategies: A systematic review of the research. Environ. Educ. Res. 2019, 25, 791-812. [CrossRef]

10. UN (United Nations). Transforming Our World: The 2030 Agenda for Sustainable Development. Resolution adopted by the General Assembly on 25 September 2015. A/RES/70/1. UN General Assembly; Seventieth Session. Agenda items 15 and 116; United Nations: New York, NY, USA, 2015.

11. Hermans, M.; Korhonen, J. Ninth graders and climate change: Attitudes towards consequences, views on mitigation, and predictors of willingness to act. Int. Res. Geogr. Environ. Educ. 2017, 26, 223-239. [CrossRef]

12. Hadjichambis, A.C.; Paraskeva-Hadjichambi, D.; Ioannou, H. Integrating Sustainable Consumption into Environmental Education: A Case Study on Environmental Representations, Decision Making and Intention to Act. Int. J. Environ. Sci. Educ. 2015, 10, 67-89.

13. Novo, M. Educación ambiental y transición ecológica. Rev. Ambient. 2018, 125, 32-41.

14. Reid, A. Climate change education and research: Possibilities and potentials versus problems and perils? Environ. Educ. Res. 2019, 6, 767-790. [CrossRef]

15. Sakellari, M.; Skanavis, C. Environmental Behavior and Gender: An Emerging Area of Concern for Environmental Education Research. Appl. Environ. Educ. Commun. 2013, 12, 77-87. [CrossRef]

16. Olsson, D.; Gericke, N. The effect of gender on students' sustainability consciousness: A nationwide Swedish study. J. Environ. Educ. 2017, 48, 357-370. [CrossRef]

17. Danielraja, R. A Study of Environmental Awareness of Students at Higher Secondary Level. Shanlax Int. J. Educ. 2019, 7, 6-10. [CrossRef]

18. Creswell, J.W. Research Design. Qualitative, Quantitative, and Mixed Methods Approaches, 4th ed.; Sage Publications: London, UK, 2014.

19. Miles, M.B.; Huberman, A.M.; Saldaña, J. Qualitative Data Analysis: A Methods Sourcebook, 3rd ed.; SAGE: Los Angeles, CA, USA, 2014.

20. Saukani, N.; Ismail, N.A. Identifying the Components of Social Capital by Categorical Principal Component Analysis (CATPCA). Soc. Indic. Res. 2019, 141, 631-655. [CrossRef]

21. Etikan, I.; Bala, K. Sampling and Sampling Methods. Biom. Biostat. Int. J. 2017, 5, 215-217. [CrossRef]

22. Gozalbo, M.E.; Tójar-Hurtado, J.C. Identifying key issues for university practitioners of garden-based learning in Spain. J. Environ. Educ. 2020, 51, 246-255. [CrossRef]

23. Denzin, N.K.; Lincoln, Y.S. The Landscape of Qualitative Research; Sage Publications: New Delhi, India, 2012.

24. Modikela Nkoana, E. Exploring the effects of an environmental education course on the awareness and perceptions of climate change risks among seventh and eighth grade learners in South Africa. Int. Res. Geogr. Environ. Educ. 2020, 29, 7-22. [CrossRef]

25. Li, C. Essays on Climate Change Mitigation, Building Energy Efficiency, and Urban Form. Ph.D. Thesis, The University of North Carolina, Chapel Hill, NC, USA, 2018. 
26. García-Díaz, J.E. Los Problemas de la Educación Ambiental: ¿Es Posible una Educación Ambiental Integradora? Centro Nacional de Educación Ambiental: Madrid, Spain, 2003.

27. Jickling, B.; Sterling, S. Post-Sustainability and Environmental Education: Framing Issues. In PostSustainability and Environmental Education; Jickling, B., Sterling, S., Eds.; Palgrave Studies in Education and the Environment; Palgrave Macmillan Springer: Cham, Switzerland, 2017; pp. 1-11. [CrossRef]

28. Tesa-Alosno, M.G. Comunicación y Representaciones del Cambio Climático: El Discurso Televisivo y el Imaginario de los Jóvenes Españoles. Ph.D. Thesis, Universidad Complutense de Madrid, Madrid, España, 2016.

(C) 2020 by the authors. Licensee MDPI, Basel, Switzerland. This article is an open access article distributed under the terms and conditions of the Creative Commons Attribution (CC BY) license (http://creativecommons.org/licenses/by/4.0/). 